\title{
Selenium-sulphur effects on the chemical composition of alfalfa (Medicago sativa L. cv. Verko)
}

\author{
F. Garousi \\ J. M. Greef \\ e-mail: garousie393@gmail.com \\ e-mail: joerg-michael.greef@julius-kuehn.de \\ Julius Kühn-Institut, Institute for Crop and Soil Science, \\ 38116 Braunschweig Bundesallee 50, Germany
}

\begin{abstract}
Selenium (Se) is an essential micronutrient, and the ability of some crops to accumulate Se is crucial for human and animal nutrition and health. Se deficiency can cause white muscle disease characterized by muscle weakness, heart failure, unthriftiness, and death in livestock. This study was undertaken to investigate the effect of sulphur (S) on Se concentration in alfalfa (Medicago sativa L. cv. Verko) as a nonhyperaccumulator plant. Alfalfa plants grown in the field were treated foliarly with $3 \mathrm{~g}$ Se ha ${ }^{-1}$ solutions of selenate, $3 \mathrm{~g} \mathrm{~S}$ ha ${ }^{-1}$ sulphate, and both. The concentration of Se in both the leaves and stems of plants was similar in the control and S-treated plants. Se concentration in plants treated with $\mathrm{S}$ was undetectable, as expected. S was shown to enhance Se accumulation in alfalfa. Furthermore, although foliar $\mathrm{Se}+\mathrm{S}$ spray increased biomass, photosynthetic pigments decreased peroxidase activity and malondialdehyde content. Overall, results suggested that foliar Se $+\mathrm{S}$ spray can be applied as a biofortification to improve alfalfa plants with appropriate amounts of Se and better nutritional as well as functional quality.
\end{abstract}

Keywords and phrases: alfalfa, non-hyperaccumulator, selenium, sulphur 


\section{Introduction}

Selenium (Se) is a metalloid that resembles sulphur (S). As an essential micronutrient and component of seleno-amino acids and seleno-proteins for animals, many prokaryotes and some algae, Se is needed for good health in small amounts. Se has an important place for antioxidant defences and is a cofactor for the antioxidant enzyme glutathione peroxidase ( $L u$ et al., 2010; Fariduddin et al., 2014; Lehotai et al., 2016). Selenium, a non-essential element for plants, plays many beneficial roles in them (Hartikainen et al., 2000; Cartes et al., 2005). Selenium enters the food chain through plants, and increasing evidence has shown that Se promoted the plant growth and, exogenous application of Se significantly increased chlorophyll a and b as well as carotenoid content in plant leaves (Filek et al., 2009; Malik et al., 2012). New findings have approved that in low concentrations Se can prevent plants from oxidative stress (Barbara et al., 2014). In contrast, as extra-Se affects growth and chlorophyll synthesis, it could be toxic because it is important in the formation of reactive oxygen species (ROS) that cause oxidative stress (Bañuelos et al., 2010; Cabannes et al., 2011). To prevent extra-ROS in plant cells, nonenzymatic antioxidants, such as antioxidative enzymes, have important roles (Dai et al., 2015). In higher plants, Se is taken up at the root level through the sulphate transporters. After uptake, Se may remain in inorganic form or get metabolized into seleno-cysteine or seleno-methionine through the sulphate assimilation pathway (Terry \& Zayed, 2000). As Se and sulphur (S) are chemically similar, Se can affect $\mathrm{S}$ homeostasis, redox status, and protein folding (De Kok \& Kuiper, 1986). Seleno-amino acids could be combined with protein instead of cysteine and methionine and then cause misfolding events that may trigger ubiquitination and subsequent degradation of protein (Sabbagh \& Van Hoewyk, 2012).

Alfalfa is an important leguminous forage that has a wide distribution in the world, and it is an important component of the agroecosystem (Deng et al., 2014; Fan et al., 2015). The agronomic biofortification of different food crops with Se could lead to a suitable strategy for increasing the intake of Se by animals and humans and reveal Se malnutrition problems (Poblaciones et al., 2014; Malagoli et al., 2015). Se fertilizers would be one agronomic practice for Se biofortification to increase Se bioavailability in plants (Poblaciones et al., 2014; Smolen et al., 2016).

There is limited evidence to suggest increased growth or other beneficial effects of Se for non-accumulator plants. Also, there is no known physiological mechanism involved in Se accumulation, translocation, and the characteristics 
of Se/S discrimination in alfalfa as a Se non-accumulator. In this regard, we have grown alfalfa to figure out the effect of foliarly applied sulphate and selenate as well in different parts of the plant, with their possible effects on the antioxidant mechanism and growth.

\section{Materials and methods}

Alfalfa (Medicagosativa L. cv. Verko) seeds were grown in acidic soil in a field in Braunschweig ( $\mathrm{N}: 52^{\circ} 17^{\prime}$, E: $10^{\circ} 26^{\prime}, 81 \mathrm{~m}$ above sea level). Seeds were sown on May 25 on four blocks, each with five $9 \mathrm{~m} \times 12 \mathrm{~m}$ distributed plots, randomly. Foliar spraying with sodium selenate (Se) at a concentration of $3 \mathrm{~g}$ Se ha ${ }^{-1}$, sodium sulphate (S) at a concentration of $3 \mathrm{~g} \mathrm{~S} \mathrm{ha}^{-1}$, and sodium selenate + sodium sulphate $(\mathrm{Se}+\mathrm{S})$, each at a concentration of $3 \mathrm{~g}$ $\mathrm{Se} \mathrm{ha}^{-1}$ and $3 \mathrm{~g} \mathrm{~S} \mathrm{ha}{ }^{-1}$, was performed at the five-leaf stage on 19 June. Control plants were sprayed with water. Four treatments, Se, S, Se + S, and control were applied as follows. Spraying was performed in calm weather by spray truck. On all plot margins, plants from the outer $1.5 \mathrm{~m}$ were discarded for minimizing the possibility of effects of the treatment from a neighbouring plot. In each plot, the central parts were harvested and analysed. During the experiment, the average mean temperature was $16^{\circ} \mathrm{C}$, and during the same period the amount of precipitation was $268.5 \mathrm{~mm}$ : $135.7 \mathrm{~mm}$ before the foliar treatment and $132.9 \mathrm{~mm}$ after the treatment. The plants were harvested after 75 days at the late stage of flowering, and ten replicates were obtained for every treatment.

\section{Photosynthetic pigment measurement}

Intact and erect leaves from 10 plants in each block were sampled for the extraction and determination of the photosynthetic pigments. The instrument settings and parameters were the same as described previously (Garousi et al., 2016).

\section{Malondialdehyde content}

The malondialdehyde (MDA) content was measured from leaves based on Zhang and Huang's method (Zhang \& Huang, 2013). 
Peroxidase (POX) activity

The peroxidase activity of leaves was assayed following Sanchez et al.'s method (Sanchez et al., 1995).

Total soluble protein content

Total soluble protein content of leaves was determined using the method followed by Bradford (Bradford, 1976).

Dry mass measurement

Above-ground parts of samples were collected at the late stage of flowering and separated into different parts of the leaves and stems. All samples were freeze-dried (ALPHA 1-4, Osterode am Herz, Germany) and milled (Fritsch, Pulverisette 7, Idar-Oberstein, Germany). These two parts were weighed using an analytical scale with an accuracy of $0.001 \mathrm{~g}$ (OHAUS Explorer, Switzerland) to record their dry masses.

Quantification of total Se and sulphur

The instrument settings and parameters were the same as described previously (Garousi et al., 2017).

\section{Data analysis}

Data were analysed statistically by SPSS 19.0 software (2010). Standard error was calculated, and analysis of variance (ANOVA) was done on the data to detect the minimum significance difference (Tukey) between treatment means with the level of significance at $\mathrm{P} \leq 0.05$.

\section{Results}

\section{Photosynthetic pigments}

Among all treatments, the concentrations of photosynthetic pigments were the highest in $\mathrm{Se}+\mathrm{S}$ and the lowest in $\mathrm{S}$. The contents of photosynthetic pigments are shown in Table 1. Concentrations of chlorophyll $\mathrm{a}, \mathrm{b}$ and carotenoids were significantly increased by about $15.7,25.2$, and $18.7 \%$, respectively, in $\mathrm{Se}+\mathrm{S}$ treatments, compared to those with $\mathrm{S}$ exposure. Se samples were gradually increased in comparison with those under control conditions. 


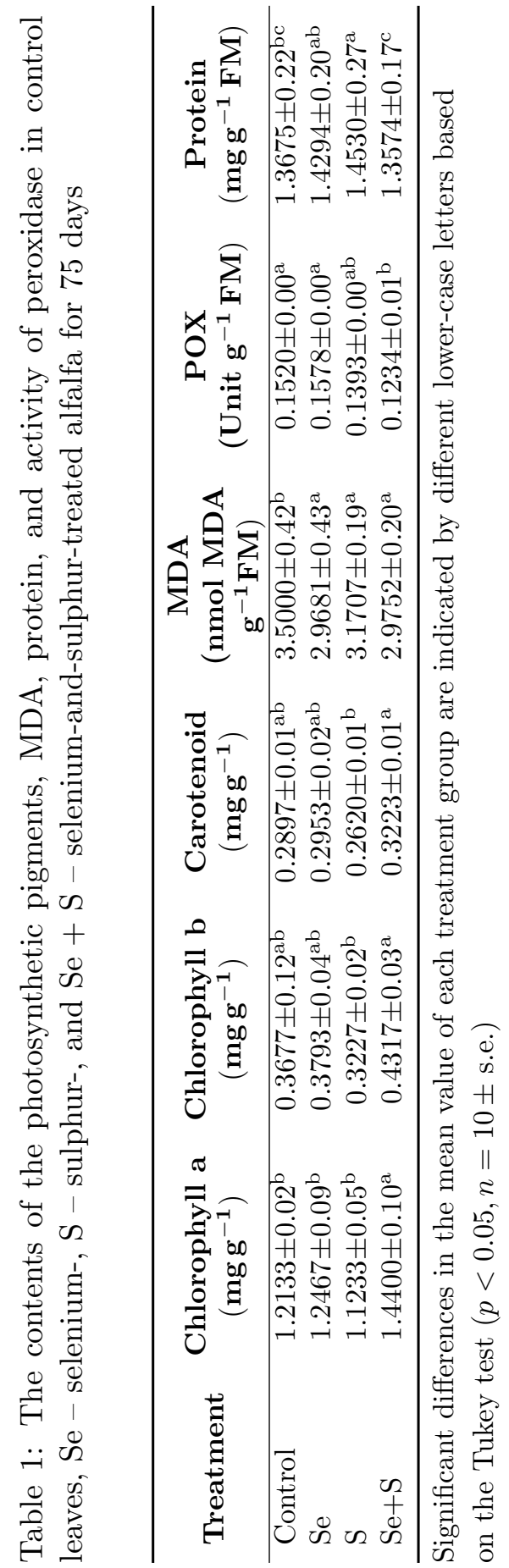




\section{Malondialdehyde content}

Compared to the control plants, the concentrations of MDA decreased in the three treatments when exposed to Se (by 15.2), $\mathrm{Se}+\mathrm{S}$ (by 15.0), and $\mathrm{S}$ (by $9.4 \%$ ) (Table 1).

Peroxidase (POX) activity

Under Se exposure, the activity of POX was enhanced by $3.7 \%$ in comparison with those under control conditions. In contrast, under $\mathrm{S}$ and $\mathrm{Se}+\mathrm{S}$ exposure, POX was inhibited by 8.4 and $18.8 \%$, respectively, as compared to those under control conditions (Table 1).

\section{Total soluble protein content}

Sulphur significantly increased the content of soluble protein in leaves by $5.9 \%$, just as selenium, which increased the soluble protein by $4.3 \%$ compared to the control (Table 1). However, in plants which received both selenium and sulphur, the protein content dropped by $0.7 \%$.

\section{Dry mass}

After the experimental period, the biomass increment of alfalfa plants was monitored (Table 2). Total leaves and stem biomass of all treated samples was markedly higher than in those grown under control. The biomass of stem and leaves formed during $\mathrm{Se}+\mathrm{S}$ exposure was higher compared to the biomass of plants treated only with Se or S.

\section{Quantification of total Se and sulphur}

In all examined samples, alfalfa leaves accumulated significantly higher Se and $\mathrm{S}$ than stems, whereas sulphate supplementation did not change significantly the sulphur content in either leaves or stems. Selenium concentration became very low as undetectable, selenate treatment caused 5- and 3-fold higher Se in leaves and stems, respectively. Furthermore, the concentration of Se in both the leaves and stem parts of alfalfa was 7- and 6-fold higher, respectively, in plants treated with both S and Se. Treatment with both Se and $\mathrm{S}$ did not cause significant changes in the sulphur concentration of leaves although its amount in the stems was very low, of 1-fold, in comparison with those under control conditions ( Table 2). 
Table 2: Dry mass and concentrations of Se and $\mathrm{S}$ in leaves and stems of alfalfa in control, $\mathrm{Se}-$ selenium, $\mathrm{S}-$ sulphur, and $\mathrm{Se}+\mathrm{S}-$ selenium and sulphur treatments

\begin{tabular}{cccc}
\hline Treatment & Dry mass $(\mathrm{g})$ & $\mathbf{S e}\left(\mathbf{m g ~ k g}^{\mathbf{- 1}}\right)$ & $\mathbf{S e}\left(\mathrm{g} \mathrm{kg}^{-\mathbf{1}}\right)$ \\
\hline \multicolumn{4}{c}{ leaves } \\
\hline Control & $0.7901 \pm 0.05^{\mathrm{b}}$ & $0.102 \pm 0.00^{\mathrm{c}}$ & $0.33 \pm 0.1^{\mathrm{a}}$ \\
$\mathrm{Se}$ & $0.7932 \pm 0.03^{\mathrm{a}}$ & $0.543 \pm 0.01^{\mathrm{b}}$ & undetectable \\
$\mathrm{S}$ & $0.7923 \pm 0.08^{\mathrm{a}}$ & undetectable & $0.33 \pm 0.2^{\mathrm{a}}$ \\
$\mathrm{Se}+\mathrm{S}$ & $0.7932 \pm 0.05^{\mathrm{a}}$ & $0.703 \pm 0.01^{\mathrm{a}}$ & $0.35 \pm 0.1^{\mathrm{a}}$ \\
\hline \multicolumn{4}{c}{ stem } \\
Control & $0.7918 \pm 0.04^{\mathrm{b}}$ & $0.030 \pm 0.00^{\mathrm{c}}$ & $0.083 \pm 0.00^{\mathrm{b}}$ \\
$\mathrm{Se}$ & $0.7941 \pm 0.01^{\mathrm{a}}$ & $0.096 \pm 0.00^{\mathrm{b}}$ & undetectable \\
$\mathrm{S}$ & $0.7939 \pm 0.03^{\mathrm{a}}$ & undetectable & $0.085 \pm 0.00^{\mathrm{ab}}$ \\
$\mathrm{Se}+\mathrm{S}$ & $0.7944 \pm 0.06^{\mathrm{a}}$ & $0.186 \pm 0.00^{\mathrm{a}}$ & $0.094 \pm 0.00^{\mathrm{a}}$ \\
\hline
\end{tabular}

Significant differences in the mean value of each treatment group are indicated by different lower-case letters based on the Tukey test $(p<0.05, n=10 \pm$ s.e. for dry mass measurement and $n=3 \pm$ s.e. for Se and S concentrations).

\section{Discussion}

In every terrestrial plant species, the assimilation of selenium in plants occurs via the same metabolic pathway of sulphur (Barak \& Goldman, 1997). It should be noted that the absorption of selenate competes with the uptake of sulphate (Arnault \& Auger, 2006). Se contributions such as selenate cause the decline in the concentration of $\mathrm{S}$ metabolites even when there are high amounts of available sulphate (Van Hoewyk et al., 2008).

Results show some pronounced properties of non-hyperaccumulator alfalfa (Medicago sativa L. cv. Verko) with regard to Se and S accumulation and movement within the plant.

Dry mass in both the leaves and stem was significantly higher in Se-, S-, and $\mathrm{Se}+\mathrm{S}$-treated plants than in controls (Table 2). In the present study, a $3 \mathrm{~g}$ $\mathrm{Se} \mathrm{ha} \mathrm{h}^{-1}$ solution of selenate and $3 \mathrm{~g} \mathrm{~S} \mathrm{ha}^{-1}$ sulphate as well as a combination of both elements clearly caused to stimulate the biomass of alfalfa plant. The application of Se in plants increases biomass accumulation (Cheng et al., 2016) or yield (Pôldma et al., 2013). Growth-promoting Se effects have been reported in lettuce (Xue et al., 2001), ryegrass (Hartikainen et al., 1997; Hartikainen \& Xue, 1999), and soybean (Djanaguiraman et al., 2005). On the other hand, 
Se application did not have any significant effect on the dry weight of other crops such as red cabbage that was treated with a $0.025 \mathrm{mM}$ aqueous solution of selenate every second day for two months or a $6.3 \mathrm{mM}$ solution used twice in the test period in fertilized soil (Mechora et al., 2011), red chicory sprayed with an aqueous solution of sodium selenate $(12.6 \mathrm{mM})$ foliarly twice (Germ et al., 2007), and potato cultivated in quartz sand and fertilized once a week with sodium selenate, the amounts corresponding to $0.075 \mathrm{mg}$ and $0.3 \mathrm{mg} \mathrm{Se}$ $\mathrm{kg}^{-1}$ (Turakainen et al., 2004).

The application of $\mathrm{Se}+\mathrm{S}$ significantly increased photosynthetic pigment content (chlorophyll a, chlorophyll b, and total carotenoids). Previous works have shown useful influences of Se on chlorophyll contents in various crops such as spinach (Saffaryazdi et al., 2012) and wheat (Yao et al., 2009). Due to the positive effects of Se and S, an increase in chlorophyll content could be seen in terms of chlorophyll synthesis, the degradation of chlorophyll could be prevented, or both (Yao et al., 2010; Wang, 2011; Iqbal et al., 2015). This kind of useful Se effects on the biosynthesis of photosynthetic pigments by protecting chloroplast enzymes have been seen in leaves of spinach (Pennanen et al., 2002). In the work, the individual application of Se and S did not have any significant effect on the photosynthetic pigments, while foliar S applications reduced them (Table 1 ).

Foliar applications of Se and Se $+\mathrm{S}$ reduced leaf MDA content (Table 1). The decline of Se-mediated in MDA may be attributed to its useful effect and to activating the antioxidants in stressed plants (Pukacka et al., 2011). Moreover, Se could act as an antioxidant and reduce the amount of ROS (Filek et al., 2008), perhaps due to its metabolism regarding selenite and then regarding the volatile dimethylselenide (Pilon-Smits et al., 1998). The findings suggested that foliar Se and $\mathrm{Se}+\mathrm{S}$ acted as both a ROS quencher and an increaser of antioxidant activity, whereupon reducing lipid peroxidation.

Whereas the foliar application of Se increased the effect of POX activity in alfalfa plants, $\mathrm{Se}+\mathrm{S}$ treatment caused reduction in its activity (Table 1). Previous works showed that the application of Se did not change antioxidant activities (Tan et al., 2012), while Khattab (2004) found that Se-mediated changes caused significant decline in antioxidant enzymatic activities. On the other hand, applications of Se caused an increase of enzymatic antioxidant capacity in plants exposed to various stresses (Hu et al., 2013a, b; Iqbal et al., 2015). As several results suggest, we may conclude that Se effects are based on concentration ( Hu et al., 2013a, b), type of stress, and crop species (Iqbal et al., 2015).

The foliar application of Se causes sulphur replacement in amino acids, with 
further changes in the protein three-dimensional structure and also causing the impairment of enzymatic function (Amweg et al., 2003). The findings of this work therefore showed that $\mathrm{Se}+\mathrm{S}$ concentration reduced protein content, whereas $S$ treatment significantly improved protein content compared to those of the non-treated control plants (Table 1).

Se concentration was greater both in the stem and the leaves of plants treated foliarly with Se (Table 2). Se application has been reported to result in a significant increase of Se content in several plant species (Drahoňovský et al., 2016). Se and S metabolism in plants are highly related to each other (Terry et al., 2000), and therefore it was recommended to investigate their possible interactions with regard to Se and $\mathrm{S}$ concentration in Se, S, and $\mathrm{Se}+\mathrm{S}$-treated plants. In non-hyperaccumulator species, Se is regarded to be accumulated non-specifically by the sulphate transport system (Persans \& Salt, 2000; White et al., 2004). There is plenty of evidence that sulphate transporters also transport selenate: mutants with non-functional sulphate transporter genes show selenate resistance (Shibagaki et al., 2002; White et al., 2004), and the overexpression of a sulphate transporter led to an increase in selenate uptake (Terry et al., 2000). In non-hyperaccumulator species, sulphate transporters were not reported to have a preference for sulphate over selenate. Therefore, their activity affects the uptake of Se and S alike, showing the observed positive correlation between tissue Se and S levels (Pence et al., 2000; Papoyan \& Kochian, 2004; Weber et al., 2004). The concentration of Se in alfalfa was higher in Se + S-treated plants than in leaves as well as in stems of plants treated with Se alone. This finding shows that $\mathrm{S}$ did not have any negative effect on Se accumulation in alfalfa plants. Also, selenate can compete with sulphate in growth media, stimulate the sulphate starvation pathway, and activate sulphate transporters, thus causing a higher selenate accumulation (Sors et al., 2005). This could be adjusted for foliarly fertilized plants, and, if so, it may be the reason for a higher Se concentration in Se + Streated alfalfa plants mentioned in the present work than in plants treated with just Se.

On a global scale, Se shortage in livestock diets is very usual, and natural supplements provide a very good source of this element. According to the concentration of Se in alfalfa, an adequate amount of Se + S-treated plants can provide an Se supplement dose that has been associated with reduced risk of white muscle disease, reproductive and production losses, and immune system dysfunction (Filley et al., 2007). 


\section{Conclusions}

The present work has shown that the foliar spray of Se, S, and Se $+\mathrm{S}$ causes a higher concentration of Se in plants treated with $\mathrm{Se}+\mathrm{S}$ than in plants treated with Se or S alone. Furthermore, $\mathrm{Se}+\mathrm{S}$ treatment increases biomass and photosynthetic pigments, whereas it decreases malondialdehyde content and peroxidase activity in these plants as non-hyperaccumulators. The effect of $\mathrm{S}$ on Se accumulation in plants can be regarded as a strategy for the safe development of Se-rich crops.

\section{Conflict of interest}

The authors declare that there are no conflicts of interest.

\section{Acknowledgements}

We appreciate the contribution of Dr Wolfgang Büchs and Dr Frank Höppnerin from the Julius Kühn-Institut in setting up the experiments outlined in our study.

\section{References}

[1] E. L. Amweg, D. L. Stuart, D. P. Weston, Comparative bioavailability of selenium to aquatic organisms after biological treatment of agricultural drainage water. Aquatic Toxicology, 63. (2003) 13-25.

[2] I. Arnault, J. Auger, Seleno-compounds in garlic and onion. Journal of Chromatography A, 1112. (2006) 23-30.

[3] G. S. Bañuelos et al., Selenium accumulation, distribution, and speciation in spineless prickly pear cactus: A drought- and salt-tolerant, selenium-enriched nutraceutical fruit crop for biofortified foods. Plant Physiology, 155. (2010) 315-327.

[4] P. Barak, I. L. Goldman, Antagonistic relationship between selenate and sulfate uptake in onion (Allium cepa): Implications for the production of organosulfur and organoselenium compounds in plants. Journal of Agricultural and Food Chemistry, 45. (1997) 1290-1294. 
[5] H. N. Barbara, D. Slawomir, W. Malgorzata, Selenium affects physiological parameters and phytochelatins accumulation in cucumber (Cucumis sativus L.) plants grown under cadmium exposure. Scientia Horticulturae, 172. (2014) 10-18.

[6] M. Bradford, A rapid and sensitive method for the quantitation of microgram quantities of protein utilizing the principle of protein-dye binding. Annals of Botany, 72. (1976) 248-254.

[7] E. Cabannes, P. Buchner, M. R. Broadley, M. J. Hawkesford, A comparison of sulfate and selenium accumulation in relation to the expression of sulfate transporter genes in Astragalus cultivars. Plant Physiology, 157. (2011) 2227-2239.

[8] P. Cartes, L. Gianfreda, M. L. Mora, Uptake of selenium and its antioxidant activity in ryegrass when applied as selenate and selenite forms. Plant and Soil, 276. (2005) 359-367.

[9] B. Cheng et al., Effects of selenium and sulfur on antioxidants and physiological parameters of garlic plants during senescence. Journal of Integrative Agriculture, 15. (2016) 566-572.

[10] H. P. Dai et al., The difference in antioxidant capacity of four alfalfa cultivars in response to Zn. Ecotoxicology and Environmental Safety, 114. (2015) 312-317.

[11] L. J. De Kok, P. J. C. Kuiper, Effect of short-term dark incubation with sulfate, chloride and selenate on the glutathione content of spinach leaf discs. Plant Physiology, 68. (1986) 477-482.

[12] L. Deng, K. B. Wang, J. P. Li, Z. P. Shangguan, S. Sweeney, Carbon storage dynamics in alfalfa (Medicago sativa) fields in the hilly-gully region of the Loess Plateau, China. Clean-Soil Air Water, 42. (2014) $1253-1262$.

[13] M. Djanaguiraman, D. Durga Devi, A. K. Shanker, J. A. Sheeba, U. Bangarusamy, Selenium - An antioxidative protectant in soybean during senescence. Plant and Soil, 272. (2005) 77-86.

[14] J. Drahonovský et al., Selenium uptake, transformation and interelement interactions by selected wildlife plant species after foliar selenate application. Environmental and Experimental Botany, 125. (2016) $12-19$. 
[15] J. W. Fan et al., Changes in root morphology and physiology to limited phosphorus and moisture in a locally-selected cultivar and an introduced cultivar of Medicago sativa L. growing in alkaline soil. Plant and Soil, 392. (2015) 215-226.

[16] Q. Fariduddin, I. Yusuf Ahmad, A. Ahmad, Brassionsteroids and their role in response of plants to abiotic stresses. Plant Biology, 58. (2014) $9-17$.

[17] M. Filek et al., The protective role of selenium in rape seedlings subjected to cadmium stress. Journal of Plant Physiology, 165. (2008) 833844.

[18] M. Filek et al., Changes in wheat plastid membrane properties induced by cadmium and selenium in presence/absence of 2,4-dichlorophenoxyacetic acid. Plant Cell Tissue Organ Culture, 96. (2009) 1928.

[19] S. J. Filley, A. Pas, C. Peters, G. Bouska, J. Pirelli Oldfield, Selenium fertilization of pastures for improved forage selenium content. Journal of Animal Science, 23. (2007) 144-147.

[20] F. Garousi, B. Kovács, D. Andrási, S. Veres, Selenium phytoaccumulation by sunflower plants under hydroponic conditions. Water, Air \& Soil Pollution, 227. (2016) 3-11.

[21] F. Garousi, B. Kovács, E. Domokos-Szabolcsy, S. Veres, Biological changes of green pea (Pisum sativum L.) by selenium enrichment. Acta Biologica Hungarica, 69. (2017) 197-209.

[22] M. Germ, V. Stibilj, J. J. Osvald, I. Kreft, Effect of selenium foliar application on chicory (Cichoriumintybus L.). Journal of Agricultural and Food Chemistry, 55. (2007) 795-798.

[23] H. Hartikainen et al., Quality of the ryegrass and lettuce yields as affected by selenium fertilization. Agricultural and Food Science, 6. (1997) $381-387$.

[24] H. Hartikainen, T. Xue, The promotive effect of selenium on plant growth as triggered by ultraviolet irradiation. Journal of Environmental Quality, 28. (1999) 1272-1275. 
[25] H. Hartikainen, T. Xue, V. Piironen, Selenium as an anti-oxidant and pro-oxidant in ryegrass. Plant and Soil, 225. (2000) 193-200.

[26] K. Hu, L. Zhang, J. Wang, Y. You, Influence of selenium on growth, lipid peroxidation and antioxidative enzyme activity in melon (Cucumis melo L.) seedlings under salt stress. Acta Societatis Botanicorum Poloniae, 82. (2013a) 193-197.

[27] X. Hu et al., Seed dormancy in four Tibetan Plateau Vicia species and characterization of physiological changes in response of seeds to environmental factors. Seed Science Research, 23. (2013b) 133-140.

[28] M. Iqbal et al., Exogenously applied selenium reduces oxidative stress and induces heat tolerance in spring wheat. Plant Physiology and Biochemistry/Société Francaise Physiologie Végétale, 94. (2015) 95-103.

[29] H. Khattab, Metabolic and oxidative responses associated with exposure of Eruca sativa (Rocket) plants to different levels of selenium. International Journal of Agriculture \& Biology, 6. (2004) 1101-1106.

[30] N. Lehotai et al., Nitro-oxidative stress contributes to selenite toxicity in pea (Pisum sativum L). Plant and Soil, 400. (2016) 107-122.

[31] Y. Lu et al., Seedlings growth and antioxidative enzymes activities in leaves under heavy metal stress differ between two desert plants: A perennial (Peganum harmala) and an annual (Halogeton glomeratus) grass. Acta Physiologiae Plantarum, 32. (2010) 583-590.

[32] M. Malagoli, M. Schiavon, S. dall'Acqua, E. A. Pilon-Smits, Effects of selenium biofortification on crop nutritional quality. Front Plant Science, 6. (2015) 280.

[33] J. A. Malik et al., Selenium antagonises the toxic effects of arsenic on mungbean (Phaseolus aureus Roxb.) plants by restricting its uptake and enhancing the antioxidative and detoxification mechanisms. Environmental and Experimental Botany, 77. (2012) 242-248.

[34] V. Mechora, Š. Stibilj, T. Radešček, A. Gaberščik, M. Germ, Impact of Se (VI) fertilization on Se concentration in different parts of red cabbage plants. Journal of Food, Agriculture and Environment, 9. (2011) 357361. 
[35] A. Papoyan, L. V. Kochian, Identification of Thlaspica erulescens genes that may be involved in heavy metal hyperaccumulation and tolerance. Characterization of a novel heavy metal transporting ATPase. Plant Physiology, 136. (2004) 3814-3823.

[36] N. S. Pence et al., The molecular physiology of heavy metal transport in the $\mathrm{Zn} / \mathrm{Cd}$ hyperaccumulator Thlaspica erulescens. Proceedings of the National Academy of Sciences U.S.A., 97. (2000) 4956-4960.

[37] A. Pennanen, T. Xue, H. Hartikainen, Protective role of selenium in plant subjected to severe UV irradiation stress. Journal of Applied Botany, 76. (2002) 66-76.

[38] M. W. Persans, D. E. Salt, Possible molecular mechanisms involved in nickel, zinc, and selenium hyperaccumulation in plants. Biotechnology \& Genetic Engineering Reviews, 17. (2000) 389-413.

[39] E. A. H. Pilon-Smits et al., Selenium volatilization and assimilation by hybrid poplar (Populus tremula x alba). Journal of Experimental Botany, 49. (1998) 1889-1892.

[40] M. J. Poblaciones, S. Rodrigo, O. Santamaria, Y. Chen, S. P. McGrath, Agronomic selenium biofortification in Triticum durum under Mediterranean conditions: From grain to cooked pasta. Food Chemistry, 146. (2014) 378-384.

[41] P. Põldma, U. Moor, T. Tõnutare, K. Herodes, R. Rebane, Selenium treatment under field conditions affects mineral nutrition, yield and antioxidant properties of bulb onion (Allium cepa L.). Acta Scientiarum Polonorum Hortorum Cultus, 12. (2013) 167-181.

[42] S. Pukacka, E. Ratajczak, E., Kalemba, The protective role of selenium in recalcitrant Acer saccharum L. seeds subjected to desiccation. Journal of Plant Physiology, 168. (2011) 220-225.

[43] M. Sabbagh, D. Van Hoewyk, Malformed selenoproteins are removed by the ubiquitin-proteasome pathway in Stanleyapinnata. Plant and Cell Physiology, 53. (2012) 555-564.

[44] A. Saffaryazdi, M. Lahouti, A. Ganjeali, H. Bayat, Impact of selenium supplementation on growth and selenium accumulation on spinach (Spinacia oleracea L.) plants. Notulae Scientia Biologicae, 4. (2012) 95-100. 
[45] M. Sanchez, G. Revilla, I. Zarra, Changes in peroxidase activity associated with cell walls during pine hypocotyl growth. Annals of Botany, 75. (1995) 415-419.

[46] N. Shibagaki et al., Selenate-resistant mutants of Arabidopsis thaliana identify Sultr1;2, a sulfate transporter required for efficient transport of sulfate into roots. The Plant Journal, 29. (2002) 475-486.

[47] T. G. Sors, D. R. Ellis, D. E. Salt, Selenium uptake, translocation, assimilation and metabolic fate in plants. Photosynthesis Research, 86. (2005) 373-389.

[48] S. Smolen et al., Biofortification of carrot (Daucus carota L.) with iodine and selenium in a field experiment. Front Plant Science, 7. (2016) 730 .

[49] D. X. Tan et al., Functional roles of melatonin in plants, and perspectives in nutritional and agricultural science. Journal of Experimental Botany, 63. (2012) 577-597.

[50] N. Terry, A. M. Zayed, M. P. de Souza, A. S. Tarun, Selenium in higher plants. Annual Review of Plant Physiology and Plant Molecular Biology, 51. (2000) 401-432.

[51] M. Turakainen, H. Hartikainen, M. M. Seppänen, Effects of selenium treatments on potato (Solanum tuberosum L.) growth and concentrations of soluble sugars and starch. Journal of Agricultural and Food Chemistry, 52. (2004) 5378-5382.

[52] D. Van Hoewyk et al., Transcriptome analyses give insights into seleniustress responses and selenium tolerance mechanisms in Arabidopsis. Plant Physiology, 132. (2008) 236-253.

[53] C. Q. Wang, Water-stress mitigation by selenium in Trifoliumrepens L. Journal of Plant Nutrition and Soil Science, 174. (2011) 276-282.

[54] M. Weber, E. Harada, C. Vess, E. V. Roepenack-Lahaye, S. Clemens, Comparative microarray analysis of Arabidopsis thaliana and Arabidopsis halleri roots identifies nicotianamine synthase, a ZIP transporter and other genes as potential metal hyperaccumulation factors. The Plant Journal, 37. (2004) 269-281. 
[55] P. J. White et al., Interactions between selenium and sulfur nutrition in Arabidopsis thaliana. Journal of Experimental Botany, 55. (2004) 1927-1937.

[56] T. Xue, H. Hartikainen, V. Piironen, Antioxidative and growthpromoting effect of selenium in senescing lettuce. Plant and Soil, 237. (2001) 55-61.

[57] X. Yao, J. Chu, G. Wang, Effects of selenium on wheat seedlings under drought stress. Biological Trace Element Research, 130. (2009) 283-290.

[58] X. Yao, J. Chu, C. Ba, Antioxidant responses of wheat seedlings to exogenous selenium supply under enhanced ultraviolet-B. Biological Trace Element Research, 136. (2010) 96-105.

[59] Z. Zhang, R. Huang, Analysis of malondialdehyde, chlorophyll, proline, soluble sugar, and glutathione content in Arabidopsis seedling. BioProtocol, 3. (2013) 14. 